\title{
Ultrastructure and chemical composition of the proboscis hooks of Acanthocephalus lucii (Müller, 1776) (Acanthocephala: Palaeacanthocephala) using X-ray elemental analysis
}

\author{
Tímea Brázová ${ }^{1}$, Larisa G. Poddubnaya ${ }^{2}$, Noemí Ramírez Miss ${ }^{3}$ and Vladimíra Hanzelová ${ }^{1}$ \\ ${ }^{1}$ Institute of Parasitology, Slovak Academy of Sciences, Košice, Slovakia; \\ ${ }^{2}$ I.D. Papanin Institute for Biology of Inland Waters, Russian Academy of Sciences, Borok, Yaroslavl Province, Russia; \\ ${ }^{3}$ Centro de Investigación y de Estudios Avanzados del IPN (CINVESTAV-IPN), Unidad Mérida, Mérida, Yucatan, Mexico
}

\begin{abstract}
The ultrastructure and chemical composition of the proboscis hooks and surrounding tegument of Acanthocephalus lucii (Müller, 1776), a parasite of European perch, Perca fluviatilis Linnaeus, were examined using scanning (SEM) and transmission (TEM) electron microscopy and X-ray microanalysis (EDXA). The blade of middle hooks consists of three layers: an outer homogeneous layer, an inner heterogeneous layer and a central core. TEM observation revealed the presence of hollow tubes, which spaced the central core; fibrous inner hook layer surrounded by an electron-dense margin and the basal tegumental layer filled with electron-dense bodies and outer layer. We found for the first time that the so-called 'epidermal covering' surrounding of the exposed hook blade (outer hook layer) is a modified striped portion of the tegumental layer and there are no special contact sites between these two morphologically different structures, i.e. striped layer of the syncytial tegument and following proper outer hook layer, which is a homogeneous, moderately electron-dense layer of $\sim 0.3 \mu \mathrm{m}$ in thickness. The hook root is embedded into subtegumental fibrous layer. X-ray microanalysis of both the surface and internal parts of $A$. lucii hooks demonstrated the presence of calcium, magnesium, phosphorus and sulphur. The highest concentration of sulphur was recorded at the tip of hooks, whereas the middle part of the hooks was most rich in calcium, phosphorus and magnesium. The proximal part of the hooks contained lower concentrations of sulphur, calcium and phosphorus. In the proboscis tegument, only two elements, calcium and silicon, were found. The differences observed in the chemical composition of the hook 'epidermal covering' and the proboscis tegument support our ultrastructural findings that the hook tegumental covering is a modified structure compared with that of the general proboscis tegument.
\end{abstract}

Keywords: scanning electron microscopy, energy-dispersive X-ray analysis, transmission electron microscopy, tegument, hooks

Acanthocephalus lucii (Müller, 1776) is one of the most widely distributed acanthocephalan species parasitising a broad range of freshwater fishes throughout the Palaearctic Region, including its commonest definitive host, the European perch, Perca fluviatilis Linnaeus (see Yamaguti 1963, Brattey 1986). Adult parasites survive in the fish intestine, where they absorb nutrients through the tegument while anchoring to the intestinal wall using an armed praesoma. The praesoma, consisting of a proboscis bearing hooks and an unarmed neck, provides the parasite an effective mechanism of attachment (Van Cleave 1952, Dezfuli et al. 2008). Moreover, the proboscis armature (with hooks arranged in regular patterns and numbers) possesses great systematic value and represents the principal diagnostic marker for the recognition of acanthocephalans at the species level (Van Cleave 1941, Wayland 2010).

The morphology of the proboscis, including the hooks and their arrangement, has been regularly studied by tax- onomists, but only a few detailed studies exist on the ultrastructure and chemical composition of acanthocephalan hooks (Graff and Allen 1963, Taraschewski 2000). X-ray microanalysis, a non-destructive method enabling multiple observations at the different regions on an individual specimen, has been applied in few parasite species, including acanthocephalans, monogeneans, digeneans and tapeworms, to determine which elements are present in the hard structures serving as attachment organs (Smith and Richards 1991, Shinn et al. 1995, Heckmann et al. 2012a, Radwan et al. 2012). The ultrastructure of acanthocephalan hooks has been studied more frequently (e.g. Hutton and Oetinger 1980, Taraschewski 2000, Dezfuli et al. 2008, Heckmann et al. 2012a,b), but detailed ultrastructural descriptions of the hook cytoarchitecture in species of Acanthocephalus Koelreuther, 1771 are limited.

It has also been established that fish acanthocephalans accumulate various chemical elements at much higher concentrations than their hosts (Sures et al. 1999a, Brá- 
zová et al. 2012). These elements are supposed to be utilised in different parts of the acanthocephalan body, including the hooks (Taraschewski 2000). Therefore, knowledge of the fine structure and chemical composition of proboscis hooks may help us to understand the mechanisms of uptake and storage of chemical substances, such as heavy metals and organic nutrients, and to clarify their roles in the biology of these parasites (Taraschewski 2000, Heckmann et al. 2012a).

The aim of the present study is to present data on the ultrastructure and chemical composition of the proboscis hooks in A. lucii by combining light microscopy, scanning (SEM) and transmission (TEM) electron microscopy and X-ray elemental analysis.

\section{MATERIALS AND METHODS}

Adult specimens of Acanthocephalus lucii were collected from the intestine of European perch, Perca fluviatilis, from the Ružín water reservoir, East Slovakia. For light microscopy, the parasites were rinsed in saline and subsequently fixed and stored in $70 \%$ ethanol. For microscopic observations, acanthocephalans were cleared in glycerine-ethanol for a short time and mounted as temporary preparations. Altogether, 20 males and 20 females were measured and documented using digital camera attached to a Leica DM5000B light microscope. All hook measurements are given in micrometres $(\mu \mathrm{m})$ unless otherwise stated.

For scanning electron microscopic (SEM) observations and $\mathrm{X}$-ray elemental analysis, specimens were fixed in $70 \%$ ethanol and dehydrated in a graded ethanol series, with a final change in absolute acetone, and then critical-point-dried (CPD) with liquid $\mathrm{CO}_{2}$. Parasites were mounted on SEM aluminium stubs using conductive double-sided carbon tape. Mounted specimens were gold-coated using a vacuum evaporator Eiko IB-3 for $30 \mathrm{~s}$ (approximate thickness of gold coating $20 \mathrm{~nm}$ ).

Acanthocephalans were examined using JEOL-JSM-6510LV and JEOL-JSM-6510LA scanning electron microscopes in combination with an energy dispersive X-ray analyser (EDXA, model EX-3618OD3A). Samples were imaged at $30 \mathrm{kV}$ and Xray spot analysis was performed using a $15 \mathrm{kV}$ electron beam. The counting time for each analysis was $50 \mathrm{~s}$ and the data were processed using digital imaging software attached to a computer. The weight percent (wt \%) of five chemical elements, calcium $(\mathrm{Ca})$, silicon $(\mathrm{Si})$, magnesium $(\mathrm{Mg})$, phosphorus $(\mathrm{P})$ and sulphur (S), was calculated for each specimen of $A$. lucii. The other two most common elements consistent for cytoplasm, carbon (C) and oxygen $(\mathrm{O})$, were always recorded but not included in this study. X-ray microanalysis was carried out on 10 specimens in the three different sections of the hook, the tip, middle part and proximal part (Fig. 1).

The two regions of the hook were considered: a posteriorly directed hook root deeply embedded in the base layer of the body wall and a distal, exposed curved blade. The length and width of the outer visible hook part (hook blade) were measured as indicated in Fig. 1. Internal hook structures, i.e. the outer layer of the hook, the inner layer and central core of the hook were also assessed (Fig. 2D,F). The hooks located in different parts of the proboscis were designated as follows: apical hooks of first two rows, middle hooks of fourth and fifth rows and basal hooks situated on the most posterior margin of the pro-

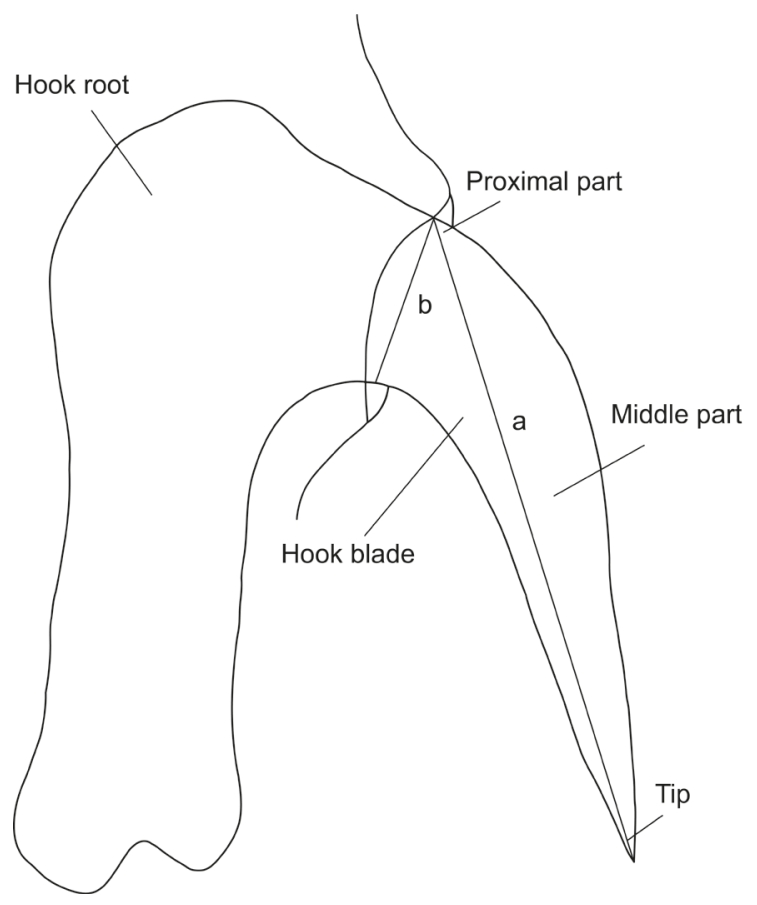

Fig. 1. Diagrammatic illustration of the parts of an acanthocephalan hook, showing the hook root and hook blade with an indication of the blade parts used for measurements.

boscis (Fig. 2A). Six apical, six middle and four basal hooks were always analysed and the measurements were taken from the proximal and middle parts and the hook tip within each hook (altogether 480 measurements). Inner composition of the hook was assessed in cross-sectioned hooks, always in triplicate measurements. Cross-section was performed approximately in the middle part of the hook using stainless steel instruments. For comparing elemental percentage in different regions (parts) of the hooks, Principal Component Analysis (PCA) and Canonical Correspondence Analysis (CCA) were used. All statistical analyses were carried out using the statistical program CANOCO 5.

Live specimens used for transmission electron microscopy (TEM) were fixed using $4 \%$ glutaraldehyde in $0.1 \mathrm{M}$ sodium cacodylate buffer $(\mathrm{pH} 7.2)$ for 16 days at $5{ }^{\circ} \mathrm{C}$, rinsed 4 times for 20 -min periods in the same buffer and postfixed in $1 \%$ osmium tetroxide for 1 hour. The material was then dehydrated in a graded series of ethanol and acetone, and embedded in Araldite and Epon. Ultrathin sections $(50-80 \mathrm{~nm})$ were stained with uranyl acetate and lead citrate, and examined using a JEOL-JEM-1011 transmission electron microscope operating at $80 \mathrm{kV}$.

\section{RESULTS}

\section{Light microscopical and SEM observation of hooks}

The proboscis of Acanthocephalus lucii is $0.51-0.75 \mathrm{~mm}$ long and $0.25-0.35 \mathrm{~mm}$ wide; it is armed with 11-14 longitudinal rows of 7-8 hooks each (Fig. 2A). The length of the outer visible hook part, hook blade, varied considerably; in the apical hooks it measured in averge 76 (range 60-93), in the middle hooks 96 (78-117) and in the basal hooks 57 (45-75) in length and 13 (9-19), 

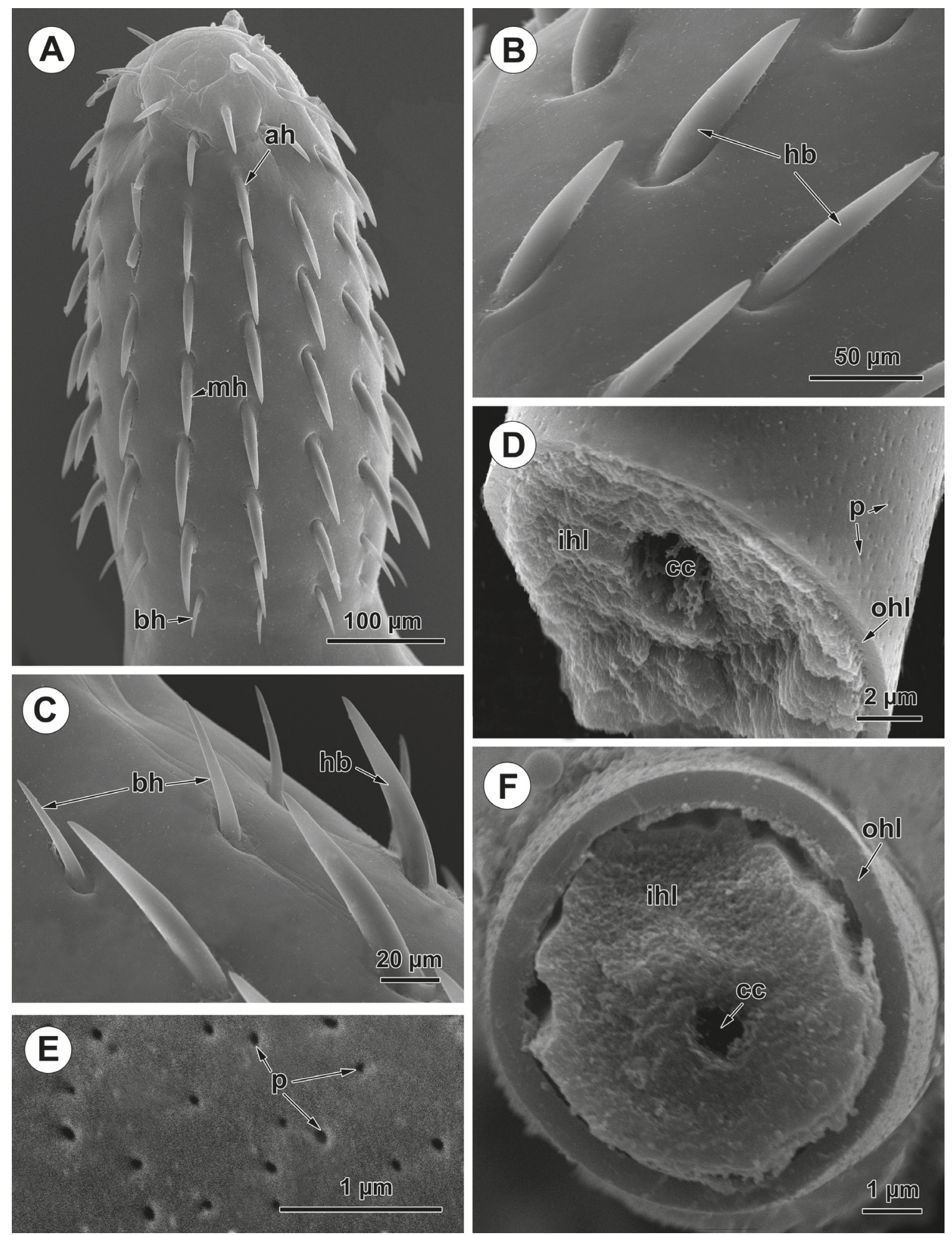

Fig. 2. SEM views of the proboscis and proboscis hooks of Acanthocephalus lucii from Perca fluviatilis. A - fully-extended proboscis; $\mathbf{B}$ - exposed blade of the middle hooks; $\mathbf{C}$ - tiny basal proboscis hooks; $\mathbf{D}, \mathbf{F}$ - cross-sections of the hooks showing the inner structure of the hook; $\mathbf{E}$ - pores on the hook surface. Abbreviations: ah - apical hooks; bh - basal hooks; cc - central core; hb - hook blade; ihl - inner hook layer; $\mathrm{mh}$ - middle hook; ohl - outer hook layer; $\mathrm{p}$ - pore.

$21(13-26)$ and $12(7-24)$ in width, respectively. SEM view of the middle region of the hook blade (Fig. 2D,F) exhibited two distinct layers: the thickness of the outer homogeneous layer was $\sim 0.6$ and that of the inner, thicker and more heterogeneous layer was $\sim 2.7$. The central core tapered distally toward the tip of the hook and measured 


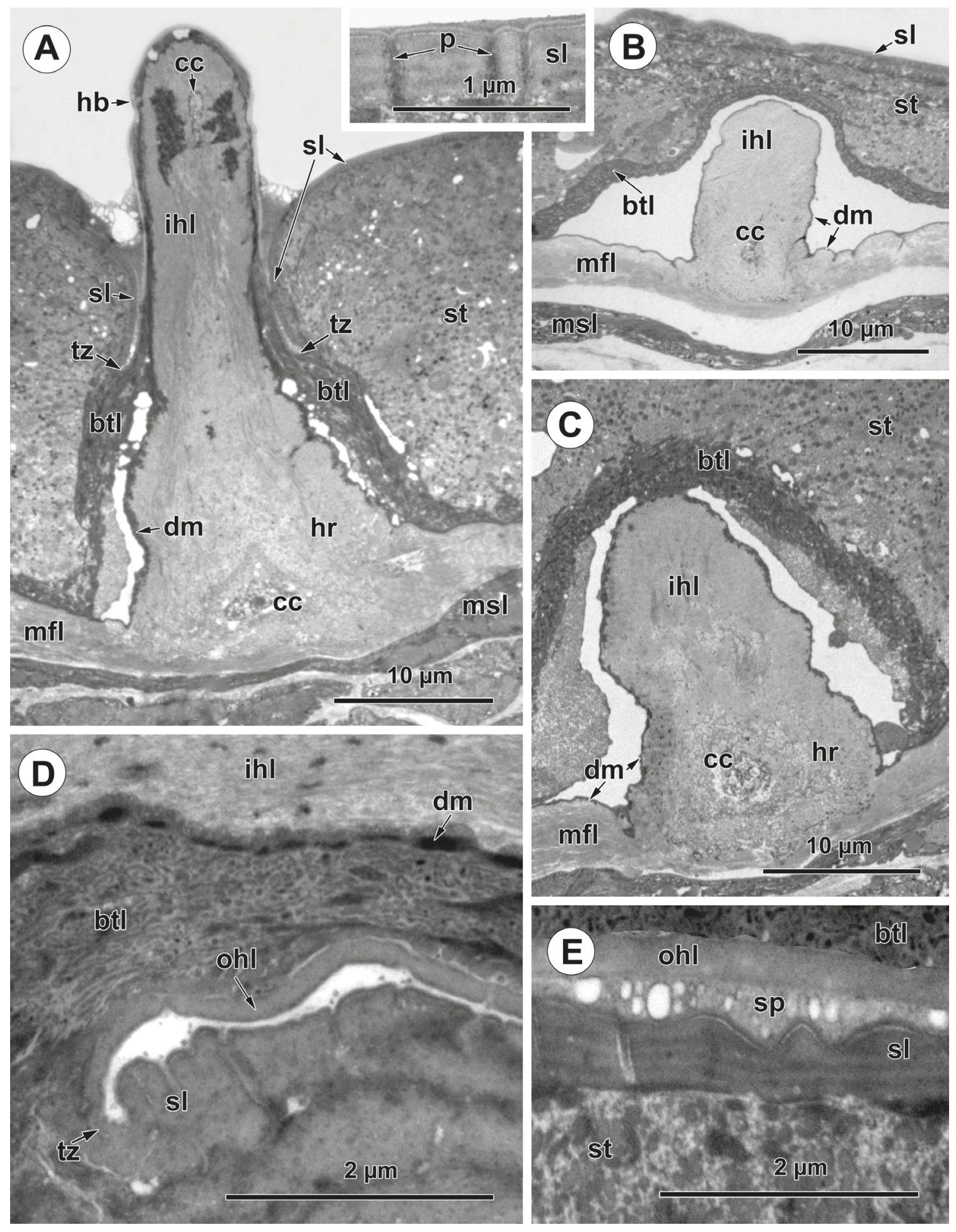

Fig. 3. TEM views of the proboscis hooks of Acanthocephalus lucii from Perca fluviatilis. A-section through the root and part of the blade; insert shows the striped layer of the proboscis tegument; note the pores contain dense material; $\mathbf{B}, \mathbf{C}$ - basal hook part; note the root of the hooks embedded in subtegumental fibrous layer; $\mathbf{D}$ - transition zone of the modification of the tegumental striped layer into the outer hook layer; $\mathbf{E}$ - section through part of the tegumental fold; note the striped layer of the tegument, the outer hook layer and part of the basal tegumental layer of the hook. Abbreviations: btl - basal tegumental layer of the hook; cc - central core of the hook; $\mathrm{dm}$ - electron-dense margin; $\mathrm{hb}$ - hook blade; $\mathrm{hr}$ - hook root; ihl - inner hook layer; $\mathrm{mfl}$ - moderately electron-dense, fibrous layer beneath the tegument; msl - muscular layer beneath the tegument; ohl - outer hook layer; $\mathrm{p}$ - pore; sl - striped layer of the tegument; sp - space between hook body and tegumental striped layer in the tegumental fold; st - syncytial tegument; tz - transition zone of modification of the tegumental striped layer into outer hook layer. 

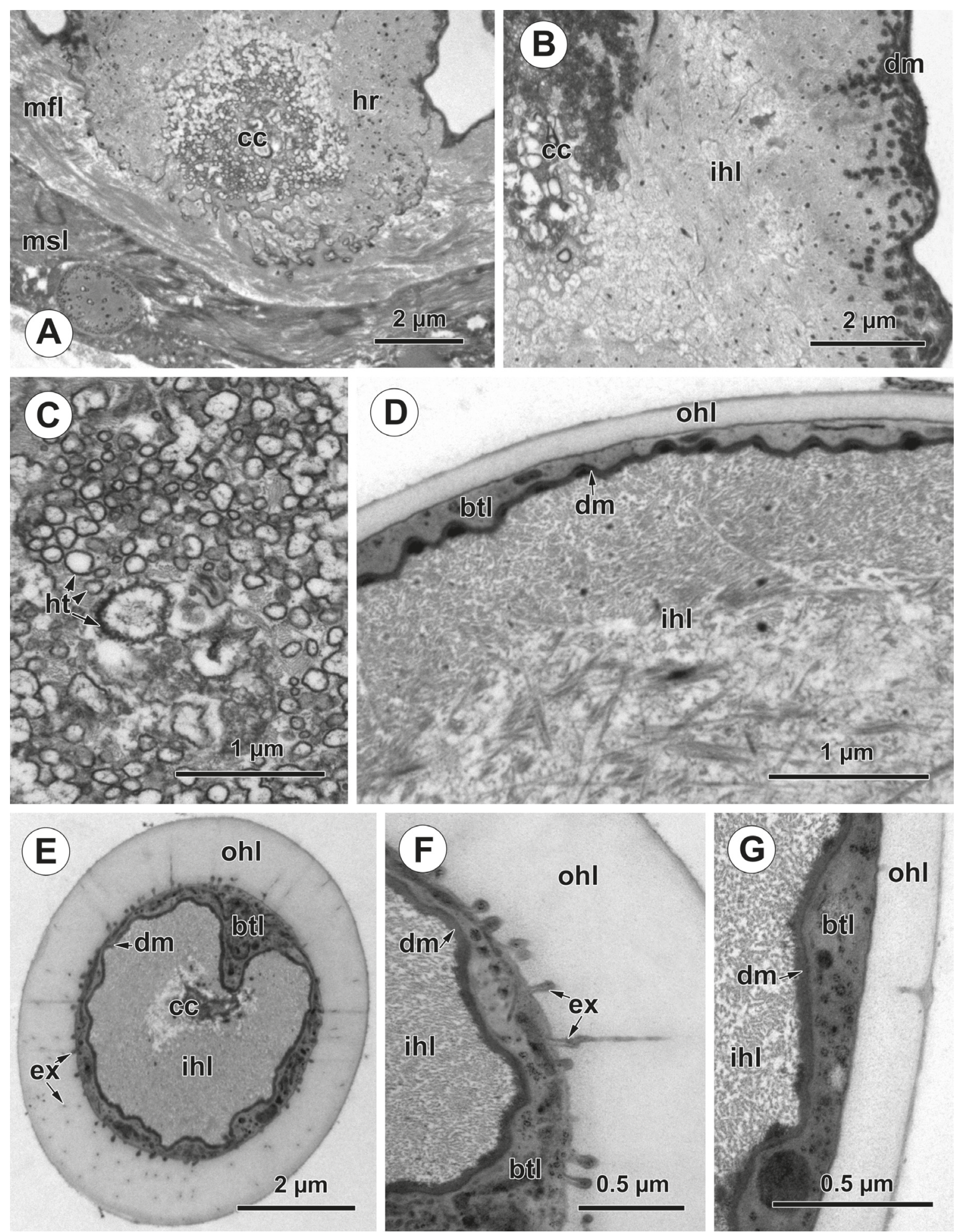

Fig. 4. Ultrastructure of the hook root and blade of Acanthocephalus lucii from Perca fluviatilis. A - hook root embedded in a fibrous layer beneath the tegument; note the underlying muscular layer; $\mathbf{B}$ - lateral view of the hook root region, showing central core, inner hook layer and electron-dense margin; $\mathbf{C}$ - structure of the central core of the hook; note hollow tubes; $\mathbf{D}$ - section through the middle part of the hook blade; note fibrous inner hook layer, narrow, dense margin, thin basal tegumental layer and outer hook layer; E-G sections through the tip of the blade; note thin extensions of the basal tegumental layer directed into outer layer of the hooks. Abbreviations: btl - basal layer of the tegument; cc - central core of the hook; dm - electron-dense margin; ex - extensions of the basal tegumental layer into outer layer of the blade tip; hr - hook root; ht - hollow tube; ihl - inner hook layer; mfl - moderately electron-dense, fibrous layer beneath the tegument; msl - muscular layer beneath the tegument; ohl - outer layer of the hook. 
Table 1. Weight percent (wt \%) of calcium (Ca), magnesium $(\mathrm{Mg})$, phosphorus $(\mathrm{P})$ and sulphur $(\mathrm{S})(\mathrm{n}=10)$ proboscis hooks and tegument of Acanthocephalus lucii from Perca fluviatilis.

\begin{tabular}{|c|c|c|c|c|}
\hline & \multicolumn{4}{|c|}{ Apical hook $(\mathrm{n}=180)$} \\
\hline & $\mathrm{Ca}$ & $\mathrm{Mg}$ & $\mathrm{P}$ & $\mathrm{S}$ \\
\hline Proximal part & $31.28 \pm 12.48$ & $1.06 \pm 0.32$ & $10.98 \pm 4.33$ & $5.51 \pm 4.13$ \\
\hline Middle part & $40.28 \pm 16.70$ & $1.12 \pm 0.23$ & $15.30 \pm 4.36$ & $2.92 \pm 4.04$ \\
\hline \multirow[t]{3}{*}{ Tip } & $8.21 \pm 7.78$ & $0.77 \pm 0.23$ & $4.77 \pm 2.49$ & $16.98 \pm 6.52$ \\
\hline & \multicolumn{4}{|c|}{ Middle hook $(\mathrm{n}=180)$} \\
\hline & $\mathrm{Ca}$ & $\mathrm{Mg}$ & $\mathrm{P}$ & $\mathrm{S}$ \\
\hline Proximal part & $32.27 \pm 15.68$ & $0.93 \pm 0.09$ & $11.71 \pm 4.50$ & $4.82 \pm 4.79$ \\
\hline Middle part & $28.10 \pm 12.84$ & $1.12 \pm 0.33$ & $13.44 \pm 3.62$ & $\begin{array}{c}12.22 \pm \\
12.27\end{array}$ \\
\hline \multirow[t]{3}{*}{ Tip } & $7.65 \pm 5.44$ & $0.49 \pm 0.17$ & $2.21 \pm 0.79$ & $20.74 \pm 3.23$ \\
\hline & \multicolumn{4}{|c|}{ Basal hook $(n=120)$} \\
\hline & $\mathrm{Ca}$ & $\mathrm{Mg}$ & $\mathrm{P}$ & $\mathrm{S}$ \\
\hline Proximal part & $26.54 \pm 19.90$ & $0.68 \pm 0.16$ & $6.79 \pm 2.68$ & $13.75 \pm 5.84$ \\
\hline Middle part & $14.04 \pm 11.39$ & $0.63 \pm 0.22$ & $6.94 \pm 2.03$ & $18.31 \pm 6.89$ \\
\hline \multirow[t]{3}{*}{ Tip } & $2.16 \pm 1.76$ & $0.00 \pm 0.00$ & $0.00 \pm 0.00$ & $11.90 \pm 2.77$ \\
\hline & \multicolumn{4}{|c|}{ Cross sections of hooks $(n=27)$} \\
\hline & $\mathrm{Ca}$ & $\mathrm{Mg}$ & $\mathrm{P}$ & $\mathrm{S}$ \\
\hline Outer layer & $19.18 \pm 5.82$ & $0.91 \pm 0.23$ & $4.76 \pm 3.33$ & $5.49 \pm 3.53$ \\
\hline Inner layer & $33.63 \pm 10.51$ & $1.04 \pm 0.22$ & $15.57 \pm 2.75$ & $0.00 \pm 0.00$ \\
\hline \multirow[t]{4}{*}{ Central core } & $51.57 \pm 10.40$ & $0.86 \pm 0.21$ & $24.40 \pm 5.95$ & $0.00 \pm 0.00$ \\
\hline & \multicolumn{4}{|c|}{ Tegument of proboscis $(n=30)$} \\
\hline & \multicolumn{2}{|c|}{$\mathrm{Ca}$} & \multicolumn{2}{|c|}{$\mathrm{Si}$} \\
\hline & \multicolumn{2}{|c|}{$4.83 \pm 4.36$} & \multicolumn{2}{|c|}{$2.23 \pm 0.82$} \\
\hline
\end{tabular}

$\sim 0.9$ in diameter (Fig. 2D,F). The hook surface with numerous openings (pores) $\sim 0.1$ in diameter (Fig. 2E).

\section{TEM observation of hooks}

Two regions can be distinguished in the syncytial structure of the proboscis tegument, which appear to be involved in hook composition: (a) an outer dense, striped layer $\sim 0.43 \mu \mathrm{m}$ in thickness, which contains bundles of filaments subdividing the region into sublayers, in which widely spaced pores are present; and (b) a basal layer of $\sim 1.8 \mu \mathrm{m}$ in thickness and containing numerous electrondense inclusions (Fig. 3A-C). The sections of the hooks show the posteriorly directed root of the hooks deeply embedded into the layer beneath the syncytial tegument (Fig. 3A-C). This is a moderately electron-dense, fibrous layer of $\sim 3.0-4.7 \mu \mathrm{m}$ in thickness. In the sections of the basal part of the hook, it can be seen that both the hook and the above-mentioned fibrous layer appear to be composed of the same electron-grey fibrils bordered by an electrondense margin (Figs. 3B,C, 4A,B). Where the hook blade is enveloped within the syncytial tegument, it is surrounded by a basal layer bordering on the electron-dense margin of the hook body (Figs. 3A,D, 4D-G). This basal tegumental layer is extended along the entire hook blade, but decreases in thickness opposite the middle region of the hook blade (Figs. 3A,D, 4D-G). Prior to the hook blade

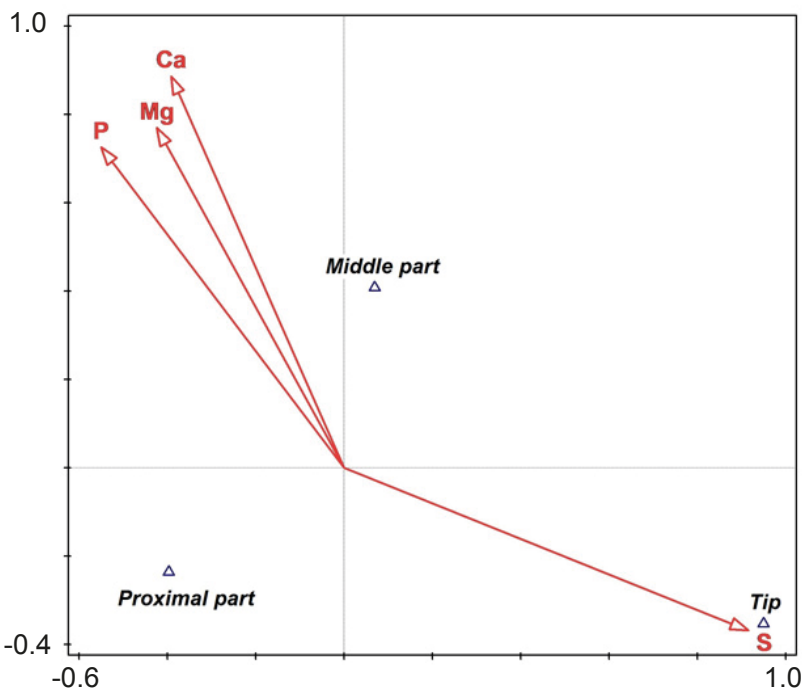

Fig. 5. Canonical correspondence analysis of the four-element content (wt \%) accumulated in different parts of the hooks of Acanthocephalus lucii.

being exposed above the tegument, an invagination of the surface tegumental striped layer is present around the embedded hook blade, forming a curved fold, on the bottom of which a transitional zone is present. In this zone the striped layer of the proboscis tegument is modified in the outer hook layer (Fig. 3A,D,E). There are no special contact sites between these two morphologically different structures, i.e. striped layer of the syncytial tegument and following proper outer hook layer (Fig. 3D,E). The outer hook layer, immediately after the hook's protrusion from the striped layer, becomes a homogeneous, moderately electron-dense layer of $\sim 0.3 \mu \mathrm{m}$ in thickness (Figs. 3D,E, 4D). Close to the distal extremity of the blade, this layer increases in thickness to $\sim 0.8 \mu \mathrm{m}$ (Fig. 4E). Thin extensions of the hook basal tegumental layer are directed into the outer hook layer in the most distal region of the hook (Fig. 4E,F). The surface organisation of the outer hook layer at the TEM level may account for the lack of pores compared to observations using the SEM. The central core of each hook is composed of material that is perforated by a number of hollow tubes and dense microfibrils (Figs. 3A-C, $4 \mathrm{~A}-\mathrm{C}$ ). This core is thickest in the basal hook portions, where it fills more than one third of the hook diameter (Fig. 4A), but decreases gradually towards the apex of the blade (Fig. 4E).

\section{$\mathrm{X}$-ray microanalysis of hooks of adults}

X-ray microanalysis of both surface and internal regions of hooks of $A$. lucii revealed the presence of calcium $(\mathrm{Ca})$, magnesium $(\mathrm{Mg})$, phosphorus $(\mathrm{P})$ and sulphur (S), all essential elements characteristic of living cells. In all parts of the proboscis hooks, Ca was the dominant element, followed by P and S. Sulphur was mostly concen- 


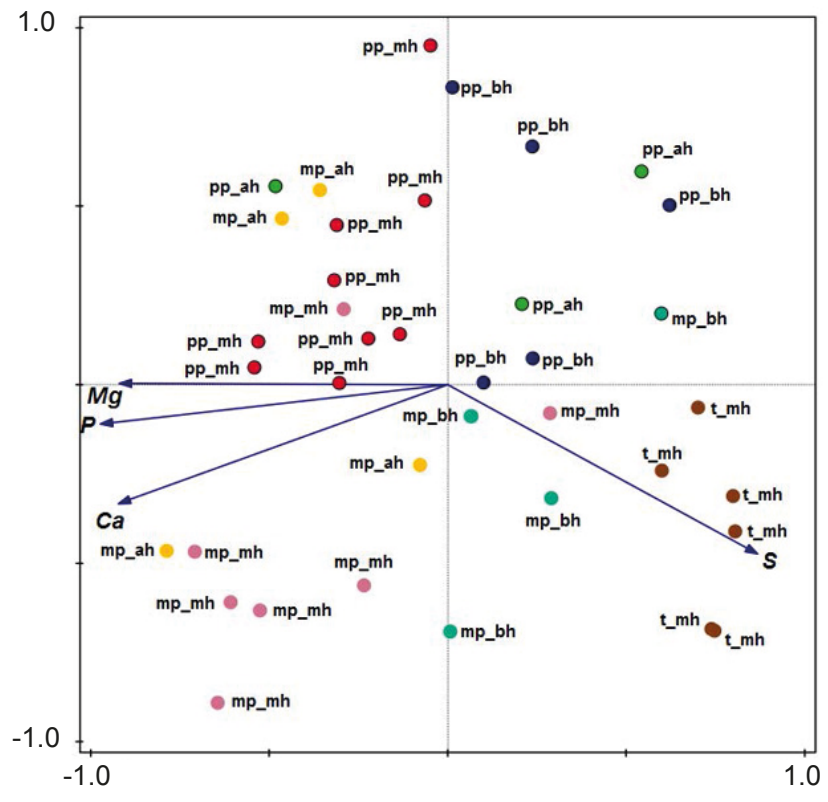

Fig. 6. Principal component analysis of the four-element content (wt \%) in hooks located in the different parts of the proboscis of Acanthocephalus lucii. Abbreviations: pp_mh - proximal part of a middle hook; pp_bh - proximal part of a basal hook; pp_ah proximal part of an apical hook; mp_bh - middle part of a basal hook; $t$ mh - tip of a middle hook; mp_mh - middle part of a middle hook; mp_ah - middle part of an apical hook.

trated at the tip of the hooks and the remaining elements in their middle regions (Table 1, Fig. 5). Considering the arrangement of hooks on the proboscis, $\mathrm{S}$ had a tendency to accumulate at the tip ( $\mathrm{t}$ ) of the middle hooks ( $\mathrm{mh}$ ), whereas $\mathrm{Ca}, \mathrm{P}$ and $\mathrm{Mg}$ prevailed in the middle part (mp) of the middle hooks (mh) (Table 1, Fig. 6). P and Mg were absent at the tip of basal hooks. Regarding the elemental content of the hook, the highest wt \% was determined in the central core (cc). Throughout the internal parts of the hook, Ca was always the most prevalent, whereas $\mathrm{S}$ was absent in the inner layer and central core of the hook (Table 1 ). A low wt $\%$ of $\mathrm{Ca}$ and silicon ( $\mathrm{Si}$ ) was recorded in the tegument close to the hooks (Table 1).

\section{DISCUSSION}

Ultrastructural details of the acanthocephalan attachment organ are of evolutionary significance (Hammond 1967, Taraschewski 2000, Wayland 2010). The present investigation into the ultrastructure and chemical composition of the proboscis hooks and surrounding tegument of Acanthocephalus lucii using both scanning and transmission electron microscopy and X-ray microanalysis revealed some new details of hook fine morphology of this palaeacanthocephalan. The present study of the inner structure of the proboscis hooks has shown four different structural layers surrounding the central core within every A. lucii hook. A fibrous subtegumental layer (equivalent to the inner heterogeneous layer observed using the SEM) is bordered by a thin, electron-dense margin. Next, the hook is enclosed by the basal region of the tegumental layer, which is conjoined to the electron-dense hook margin; however, prior to the hook blade being exposed above the tegument, it is covered by a striped portion of the tegumental layer modified into a homogeneous, moderately electron-dense outer hook layer (equivalent to the outer layer observed using the SEM).

Information pertaining to the ultrastructure of acanthocephalan hooks is rather limited. Taraschewski (2000) presented diagrammatic illustrations of hooks for the three main classes, the palaeacanthocephalans, archiacanthocephalans and eoacanthocephalans. According to his descriptions, all hooks, irrespective of the systematic affiliation of the worms, had a central cone of "connective tissue arising from the subtegumental connective tissue" (= the inner layer in our investigation). In eoacanthocephalans and palaeacanthocephalans, such as $\mathrm{Pa}$ ratenuisentis ambiguus (Van Cleave, 1921), Polymorphus minutus (Goeze, 1782) and Acanthocephalus anguillae (Müller, 1780) the cone of 'connective tissue' was also covered by tegument, so-called 'epidermal covering' (Nicholas 1967, Herlyn and Ehlers 2001, Herlyn et al. 2001). It has been suggested that such tegumental covering of the proboscis hooks of eoacanthocephalans and palaeacanthocephalans represents a secondary divergence of the oldest evolutionary lineage, the archiacanthocephalans, the hooks of which are without this covering (see Herlyn et al. 2001, Verweyen et al. 2011).

Furthermore, Hammond (1967) and Herlyn and Ehlers (2001) considered that the hooks of Acanthocephalus ranae (Schrank, 1788) and A. anguillae arise from a separate 'connective tissue' layer situated between the hypodermis and muscle layers. Our results support the assumption that the hooks of the palaeacanthocephalan A. lucii are derivatives of the fibrous layer beneath syncytial tegument and, as observed in the present study, with the involvement of the basal and outer modified parts of the tegument. We revealed for the first time that the so-called 'epidermal covering' surrounding the exposed hook blade is a modified striped portion of the tegumental layer.

Our investigation has also shown numerous pores on the outer surface of the hook of $A$. lucii as revealed SEM observation. However, TEM analysis demonstrated that these pores are only shallow invaginations of the surface epithelium, which do not penetrate deeply into the outer hook layer. In contrast, the proboscis and body tegument of acanthocephalans have the striped layer punctured by a large number of crypts that open to the surface via pores (Taraschewski 2000).

Our EDXA study of five inorganic elements has shown that acanthocephalan hooks are most composed of calcium, which is an important constituent of hard structures 
in other groups of parasites (e.g. clamp sclerites, marginal hooks and hamuli in monogeneans, digenean spines and hooks of the tapeworms - Kayton 1983, Smith and Richards 1991, Shinn et al. 1995, 2003, Radwan et al. 2012).

The distribution of $\mathrm{Ca}$ and four other elements $(\mathrm{Mg}$, $\mathrm{S}, \mathrm{P}$ and $\mathrm{Si}$ ) detected in the hooks and closely surrounding regions varied. The highest concentration of $\mathrm{S}$ was recorded at the tip of hooks, whereas the middle parts of the hooks mainly contained greater amounts of $\mathrm{Ca}, \mathrm{P}$ and Mg. Heckmann et al. (2012b) also revealed the highest concentrations of $\mathrm{S}$ at the tip of acanthocephalan hooks, whereas the centre of the hooks was rich in $\mathrm{Ca}$ and $\mathrm{P}$.

Shinn et al. (1995) also showed variation in the amounts of $\mathrm{S}$ in the hamulus of species of Gyrodactylus von Nordmann, 1832 (Monogenea), with the root of the hamulus having the lowest $\mathrm{S}$ content and the shaft, point and ventral and dorsal bar attachment points of the hamulus higher levels. Great variation of the chemical composition of tegumental spines of some digenean species has also been reported by Radwan et al. (2012). These authors inferred that the diverse distribution of S, Ca and $P$ could be attributed to the presence of the elements in the habitat and the ability of distinct parasites to metabolise and utilise them.

The attachment organs of acanthocephalans may have a high rigidity for fixing the parasite to the host's tissues and yet also be flexible (Heckmann et al. 2012a). Ca and P, as the dominant elements in the middle part of the hooks, form a rigid calcium phosphate apatite with disulfide bonds (thiol groups of the amino acids cysteine and cystine) and are known to provide the hardest tissues found in invertebrates and, likewise, the teeth and bones of vertebrates (Heckmann et al. 2007). The lower content of S, $\mathrm{Ca}$ and $\mathrm{P}$ in the proximal region of the hook, on the other hand, provides flexibility.

In the present study, the central core and inner layers of the hook were sulphur-free. At the point where it passes thought the surface layer of the tegument and is exposed to the environment, the hook consists only of $\mathrm{Ca}$ and $\mathrm{P}$ plus a small amount of $\mathrm{Mg}$ (possibly a replacement for Ca). Sulphur was present in the outermost layer of the hook, which may enhance its hardness and ensure the adequate attachment of the parasite to the epithelium of the host's intestine (Heckmann et al. 2012b).

Only two elements ( $\mathrm{Ca}$ and $\mathrm{Si}$ ) were detected in the proboscis tegument close to the hooks. The $\mathrm{Ca}$ content $(4.8 \pm 4.4 \mathrm{wt} \%)$ was several times lower compared to that in the proximal part of hooks. This relatively low $\mathrm{Ca}$ concentration, along with the presence of $\mathrm{Si}$, might enable the high flexibility and retractile facility of the proboscis during the attachment of the parasite to the host's tissues. Silicon is an element commonly occurring in the skin, bones and connective tissue of animals, providing flexibility in these tissues (Carlisle 1986). The differences revealed in the chemical composition of the hook 'epidermal covering' and proboscis tegument tend to support our ultrastructural observations that the hook covering is a complex, modified structure, as compared with that of the general proboscis tegument, and not just a simple tegumental covering.

A number of recent studies have confirmed that acanthocephalans have a unique ability to accumulate and store high amounts of essential elements, including calcium, copper, magnesium and zinc, from their environment (Sures et al. 1999b, Thielen et al. 2004, Jankovská et al. 2011, Brázová et al. 2012) as a consequence of competition for these elements between the fish host and its parasites and between different parasites within the helminth infrapopulation the host' intestine. Some other studies (Sures et al. 1999b, Sures 2002) pointed out that the competition for minerals may also lead to extra absorption of non-essential elements such as toxic lead and cadmium due to their similarity in chemical properties.

Significant correlations were clearly demonstrated between $\mathrm{Ca}$ and other metals in A. lucii and perch parasitehost system (Sures 2002). The author explains these interelement relations in terms of their chemical similarity, e.g. lead could be bound inside a crystal lattice instead of $\mathrm{Ca}^{2+}$ via isomorphic substitution and the similarity of atomic size of these two elements. Sures et al. (2000), who examined the accumulation and distribution of lead in an acanthocephalan Moniliformis moniliformis (Bremser, 1811) from rats, found the higher concentrations of this element in the praesoma than the metasoma. It also seems that the acanthocephalan proboscis, and most probably also the proboscis hooks, may play an important role not only in attachment but also in the uptake of elements, even toxic metals.

During evolution of the acanthocephalans, numerous unique morphological and biological adaptations occurred as a consequence of their parasitic mode of life. Due to that acanthocephalans offer a proper model system to test various hypotheses and generalisations regarding the evolution of parasitism in metazoans.

Acknowledgements. The authors would like to thank the staff of the Centre of Electron Microscopy, I.D. Papanin Institute for the Biology of Inland Waters, Russian Academy of Sciences, Borok, Russia, for technicial assistance. The authors also thank David I. Gibson, Natural History Museum, London, for corrections of an early version of the manuscript and Stanislav Géci and Rudolf Halmi, Slovak Fishing Union, for help in obtaining fish. This study was undertaken within the framework of a project of the Research \& Development Operational Programme funded by the ERDF (code ITMS: 26220120022) (0.5). The present study was also supported by the grants of the Slovak Research and Development Agency (APVV; project LPP-0151-07) and Agency of the Ministry of Education of the Slovak Republic and Slovak Academy of Sciences (VEGA; project No. 2/193/14). 
Brattey J. 1986: Life history and population biology of Acanthocephalus lucii on the pigmentation, reproduction and susceptibility to predation of the isopod Asellus aquaticus. J. Parasitol. 72: 633-645.

Brázová T., Torres J., Eira C., Hanzelová V., Miklisová D., Šalamún P. 2012: Perch and its parasites as heavy metal biomonitors in a freshwater environment: the case study of the Ružín water reservoir, Slovakia. Sensors 12: 3068-3081.

CARLisLe E.M. 1986: Silicon as an essential trace element in animal nutrition. Ciba Found Symp. 121: 123-139.

Dezfuli B.S., Lui A., Glari L., Boldrini P., Giovonazzo G. 2008: Ultrastructural study on the body surface of the acanthocephalan parasite Dentitruncus truttae in brown trout. Microsc. Res. Techn. 71: 230-235.

Graff D.J., Allen K. 1963: Glycogen content in Moniliformis dubius (Acanthocephala). J. Parasitol. 49: 204-208.

HAmmond R.A. 1967: The fine structure of the trunk and praesoma wall of Acanthocephalus ranae (Schrank, 1788) Lühe, 1911. Parasitology 57: 475-486.

Heckmann R.A., Amin, O.M., Radwan, N.A.E., Standing M.D., Eggett, D.L. 2012a: Comparative chemical element analysis using energy dispersive X-ray microanalysis (EDXA) for four species of Acanthocephala. Sci. Parasitol. 13: 27-35.

Heckmann R.A., Amin O.M., Radwan N.A., Standing M.D., Eggett D.L., El Naggar A.M. 2012b: Fine structure and energy dispersive X-ray analysis (EDXA) of the proboscis hooks of Rhadinorhynchus ornatus Van Cleave, 1918 (Rhadinorhynchidae: Acanthocephala). Sci. Parasitol. 13: 37-43.

Heckmann R.A., Amin O.M., Standing M.D. 2007: Chemical analysis of metals in acanthocephalans using energy dispersive $\mathrm{X}$-ray analysis (EDXA) in conjunction with a scanning electron microscope (SEM). Comp. Parasitol. 74: 388-391.

Herlyn H., Ehlers U. 2001: Organization of the praesoma in Acanthocephalus anguillae (Acanthocephala, Palaeacanthocephala) with special reference to the muscular system. Zoomorphology 121: 13-18.

Herlyn H., Martini N., Ehlers U. 2001: Organisation of the praesoma of Paratenuisentis ambiguus (Van Cleave, 1921) (Acathocephala: Eoacanthocephala), with special reference to the lateral sense organs and musculature. Syst. Parasitol. 50: $105-116$.

Hutton T.L., Oetinger D.F. 1980: Morphogenesis of the proboscis hooks of an archiacanthocephala, Moniliformis moniliformis (Bremser 1811) Travassas 1915. J. Parasitol. 66: 965-972.

Jankovská I., Lukešová D., SzÁková J., Langrová I., VADLEjCh J., Čadková Z., VÁlek P., Petrtýl M., Kudrnáčová M. 2011: Competition for minerals ( $\mathrm{Zn}, \mathrm{Mn}, \mathrm{Fe}, \mathrm{Cu}$ ) and $\mathrm{Cd}$ between sheep tapeworm (Moniezia expansa) and its definitive host sheep (Ovis aries). Helminthologia 48: 237-243.

Kayton R.J. 1983: Histochemical and X-ray elemental analysis of the sclerites of Gyrodactylus spp. (Platyhelminthes: Monogenoidea) from the Utah chub, Gila atraria (Girard). J. Parasitol. 69: 862-865.

Kennedy C.R. 2006: Ecology of the Acanthocephala. Cambridge University Press, New York, 249 pp.
Nicholas W.L. 1967: The biology of the Acanthocephala. Adv. Parasitol. 5: 205-246.

Radwan N.A., Abou Shafeey H.E., Khalil A.I. 2012: Chemical characterization of tegumental spines of four digenean species using energy dispersive X-ray microanalysis (EDXA). Int. J. Parasitol. Res. 4: 100-105.

Smith S.A., Richards K.S. 1991: Ultrastructure and microanalysis of the protoscolex hooks of Echinococcus granulosus. Parasitology 103: 267-274.

Shinn A.P., Bron J.E., Sommerville Ch., Gibson D.I. 2003: Comments on the mechanism of attachment in species of the monogenean genus Gyrodactylus. Invertebr. Biol. 122: 1-11.

Shinn A.P., Gibson D.I., Sommerville C. 1995: A study of the composition of the sclerites of Gyrodactylus Nordmann, 1832 (Monogenea) using X-ray elemental analysis. Int. J. Parasitol. 25: 797-805.

SURES B. 2002: Competition for minerals between Acanthocephalus lucii and its definitive host perch (Perca fluviatilis). Int. J. Parasitol. 32: 1117-1122.

Sures B., Jürges G., Taraschewski H. 2000: Accumulation and distribution of lead in the archiacanthocephalan Moniliformis moniliformis from experimentally infected rats. Parasitology 121: 427-433.

Sures B., Siddall R., Taraschewsi H. 1999a: Parasites as accumulation indicators of heavy metal pollution. Parasitol. Today 15: 16-21.

Sures B., Steiner W., Rydlo M., Taraschewski H. 1999b: Concentrations of 17 elements in the zebra mussel (Dreissena polymorpha), in different tissues of perch (Perca fluviatilis), and in perch intestinal parasites (Acanthocephalus lucii) from the subalpine Lake Mondsee, Austria. Environ. Toxicol. Chem. 18: 2574-2579.

TARASchewsi H. 2000: Host-parasite interactions in Acanthocephala - a morphological approach. Adv. Parasitol. 46: $1-179$.

Thielen F., Zimmermann S., Baska F., Taraschewski H., Sures B. 2004: The intestinal parasite Pomphorhynchus laevis (Acanthocephala) from barbel as a bioindicator for metal pollution in the Danube River near Budapest, Hungary. Environ. Pollut. 129: 421-429.

Van Cleave H.J. 1941: Hook patterns on the acanthocephalan proboscis. Q. Rev. Biol. 16: 157-172.

Van Cleave H.J. 1952: Some host-parasite relationships of the Acanthocephala, with special reference to the organs of attachment. Exp. Parasitol. 1: 305-330.

Verweyen L., Klimpel S., Palm H.W. 2011: Molecular phylogeny of the Acanthocephala (class Palaeacanthocephala) with a paraphyletic assemblage of the orders Polymorphida and Echinorhynchida. PloS ONE 6: e28285.

WAYLAND M.T. 2010: Proboscis profiler: a tool for detecting acanthocephalan morphotypes. Syst. Parasitol. 76: 159-167.

Yamaguti S. 1963: Acanthocephala. Systema Helminthum, Wiley Interscience, New York \& London, 423 pp. 